\title{
Low skeletal muscle mass assessed directly from the 3rd cervical vertebra can predict pharyngocutaneous fistula risk after total laryngectomy in the male population
}

\author{
Maria Casasayas $^{1}\left[\right.$ D Jacinto García-Lorenzo ${ }^{2} \cdot$ Beatriz Gómez-Ansón $^{3} \cdot$ Victoria Medina $^{3} \cdot$ Alejandro Fernández $^{4}$. \\ Miquel Quer ${ }^{1,5} \cdot$ Xavier León $^{1,5}$
}

Received: 3 August 2021 / Accepted: 4 October 2021 / Published online: 19 October 2021

(c) The Author(s) 2021

\begin{abstract}
Purpose Skeletal muscle mass (SMM) loss and sarcopenia have been identified as risk factors for postoperative complications. The aim of this study was to investigate the relationship between pharyngocutaneous fistula (PCF) formation after total laryngectomy (TL) and SMM assessed from a computed tomography image of the 3rd cervical vertebra (C3).

Methods Retrospective study of 86 male patients who underwent TL between 2013 and 2019 in a single institution. We excluded women from the analysis due to our limited sample. SMM was determined from cross-sectional muscle area (CSMA) measurement at C3 using the ImageJ software. Results were compared with those for the skeletal muscle mass index (SMMI) calculated from the estimated measure at 3rd lumbar vertebra (L3).

Results PCF formation occurred in 21/86 patients. According to the CSMA at a C3 cut-off of $35.5 \mathrm{~cm} 2$, of 18 patients (20.9\%) with low SMM, 9 developed PCFs (50.0\%). Among patients with normal SMM ( $n=68,79.1 \%), 12$ developed PCFs $(17.6 \%)$. The CSMA at $\mathrm{C} 3$ was the only variable significantly associated with PCF risk, which was 4.7 times greater in patients with low SMM $(p=0.007)$. Sarcopenia was more frequent in underweight patients $(p=0.0001)$, patients undergoing extended surgeries $(p=0.003)$, or presenting preoperative anaemia $(p=0.009)$ or hypoalbuminemia $(p=0.027)$.

Conclusion Measuring the CSMA at C3 obtained results equivalent to those obtained by calculating the SMMI at L3, suggesting that direct SMM assessment from C3 is a useful approach to evaluating PCF formation risk after TL.
\end{abstract}

Keywords Head and neck squamous cell carcinoma $\cdot$ Pharyngocutaneous fistula $\cdot$ Total laryngectomy $\cdot$ Sarcopenia $\cdot$ Computed tomography

Maria Casasayas

mcasasayas@santpau.cat

1 Servicio de Otorrinolaringología, Hospital de la Santa Creu i Sant Pau, Universitat Autònoma de Barcelona, C/Mas Casanovas, 90, 08041 Barcelona, Spain

2 Servicio de Otorrinolaringología, Hospital del Mar, Barcelona, Spain

3 Servicio de Radiodiagnóstico, Unidad de Neuro-Radiología, Hospital de la Santa Creu i Sant Pau, Universitat Autònoma de Barcelona, Barcelona, Spain

4 Servicio de Medicina Nuclear, Hospital de la Santa Creu i Sant Pau, Universitat Autònoma de Barcelona, Barcelona, Spain

5 Centro de Investigación Biomédica en Red de Bioingeniería, Biomateriales y Nanomedicina (CIBER-BBN), Madrid, Spain

\section{Introduction}

For some advanced laryngeal and hypopharyngeal tumours, total laryngectomy (TL) is the initial treatment or a salvage treatment after local recurrence. A postoperative complication of TL is the formation of a pharyngocutaneous fistula (PCF). While several observational studies and meta-analyses review predisposing factors for PCF formation [1-5], there is currently no consensus as to which of those factors is the most predictive. In a study performed in our hospital [6], factors identified as being significantly related to PCF formation were the extent of surgery and the presence of postoperative haemoglobin levels below $99 \mathrm{~g} / \mathrm{L}$.

A growing concern regarding the nutritional status of patients with cancer highlights sarcopenia as a risk factor for treatment-associated complications [7-12]. Sarcopenia, defined by the European Working Group on Sarcopenia in 
Older People (EWGSOP) [13] as progressive and generalized skeletal muscle impairment, is diagnosed by objectifying decreased muscle strength and altered quantity or quality of muscle tissue. Patients with head and neck carcinomas (HNSCC) frequently lose muscle mass due to the metabolic characteristics of their tumour, to its location at the level of the upper airway and digestive tract, and to important sequelae or toxicities produced by treatments [14]. The reported prevalence of sarcopenia in patients with HNSCC varies widely, from as low as 6\% [15] to as high as 77\% [9].

Of several techniques described to evaluate sarcopenia, cervical computed tomography (CT), a component of routine tumour staging studies, has been proposed as especially useful for patients with HNSCC [16]. From CT images obtained at the level of the 3 rd cervical vertebra (C3), muscle tissue can be accurately quantified so as to determine body composition. Since Swartz et al. [16] demonstrated that skeletal muscle mass ( $\mathrm{SMM}$ ) measured at $\mathrm{C} 3$ is proportional to muscle mass measured at the 3rd lumbar vertebra (L3) the standard location for quantifying SMM - that formula has been used in most studies of sarcopenia in patients with HNSCC to estimate the cross-sectional muscle area (CSMA) at $\mathrm{L} 3$ from the area measured at $\mathrm{C} 3$ [7, 10, 11, 17-20]. A skeletal muscle mass index (SMMI) is then obtained by dividing the L3 area by the squared height of the patient.

However, use of the Swartz et al. [16] formula is complicated in routine clinical practice. According to the reviewed literature, only Jung et al. [21] have evaluated diminished SMM based on measurements at C3; in that study, which included 305 patients with advanced HNSCC in different locations, grouped according to treatment (surgical vs radiotherapy \pm chemotherapy), survival was analysed according to the CSMA at the C3 level, with the authors observing that patients with a CSMA at C3 of less than $56.3 \mathrm{~cm}^{2}$ had poorer overall survival.

There is no consensus on what cut-off point should be used to define low SMM, but it is probably necessary to set a specific cut-off point for each sex due to differences in muscle constitution. Prado et al. [22], whose sex-specific cut-offs for defining sarcopenia have been used multiple times in the literature [9, 23-25], found the mean CSMA at $\mathrm{L} 3$ value to be higher in obese men than in obese women $\left(180.2 \mathrm{~cm}^{2}\right.$ and $125.1 \mathrm{~cm}^{2}$, respectively). In our institution, our female population undertaking a TL is limited; therefore, we decided to exclude women from this study.

The aim of the present study was to analyse the relationship between low SMM, as determined from the CSMA measured directly from a CT scan slice of $\mathrm{C} 3$, and postoperative PCF formation in male patients treated with TL.

\section{Materials and methods}

The study followed the ethical standards of the latest version of the Helsinki Declaration, and was evaluated and authorized by our hospital's Clinical Research Ethics Committee [reference 19/126 (OBS)]. Given the retrospective nature of the study, the informed consent of the patients included in the study was not considered necessary.

\section{Patient description}

We retrospectively reviewed all TL procedures performed consecutively between 2013 and 2019 in our hospital. For 105 of the 113 patients who underwent TL, preoperative cervical CT images were available that allowed an evaluation of the SMM. We only included patients with an available imaging test 2 months prior to the surgery (median 34.5 days, range 2-61 days); therefore, 6 patients were excluded. We excluded 13 women who underwent a TL during the study period. In total, 86 male patients were included, most of them treated with simple TL $(n=67)$, extended TL with pharyngectomy without reconstruction $(n=11)$, and extended TL with pharyngectomy and reconstruction with a pectoralis major flap $(n=8)$. All eight patients undergoing flap reconstruction had been implanted with a salivary bypass tube.

Surgery was the initial treatment in 43 cases $(50.0 \%)$, and was salvage treatment in 31 cases (36.0\%): 13 (41.9\%) after radiotherapy; 2 (6.5\%) after surgery and radiotherapy; 13 (41.9\%) after chemo-radiotherapy; and $3(9.7 \%)$ after bioradiotherapy. In the remaining 12 cases $(14.0 \%)$, the surgical indication was resection of a second tumour located in the larynx or hypopharynx of patients previously treated with radiotherapy. Of the 86 included patients, $43(50.0 \%)$ had received radiotherapy prior to surgery, and in 74 patients (86.1\%), surgical treatment included neck dissection, unilaterally in 12 cases (14.0\%) and bilaterally in 62 cases (72.1\%).

All patients received antibiotic prophylaxis, usually with amoxicillin-clavulanic acid: $2 \mathrm{~g}$ administered $30 \mathrm{~min}$ before surgery, and $1 \mathrm{~g}$ administered every $4 \mathrm{~h}$ during surgery. Patients allergic to penicillin were administered the combination clindamycin $900 \mathrm{mg}+$ gentamicin $5 \mathrm{mg} / \mathrm{kg}$. Enteral nutrition by nasogastric tube was initiated on the 1st postoperative day. If no wound complications occurred, oral intake was started on the 7th postoperative day in non-irradiated patients, and on the 12th postoperative day in patients who had previously received radiotherapy or undergone pectoralis major flap reconstruction. 


\section{Data analysis}

A fistula was defined as any clinical suspicion of salivary leak confirmed by oral administration of methylene blue dye. When a PCF was confirmed, the initial treatment was conservative management involving antibiotic therapy, continuation of enteral nutrition, and daily local wound care. In cases that did not respond adequately to conservative management, pectoralis major flap reconstruction was considered on a case-by-case basis [26].

The following patient-related variables were assessed: sex; age; alcohol use; tobacco use; diabetes mellitus; and American Society of Anesthesiologists (ASA) physical status. Patients were classified into 1 of 3 categories according to their use of alcohol and tobacco, as follows: no use; moderate use ( $<20$ cigarettes/day and/or $<80 \mathrm{~g}$ alcohol/day); or heavy use ( $\geq 20$ cigarettes/day or $\geq 80 \mathrm{~g}$ alcohol/day). The body mass index (BMI) was calculated for each patient, with patients grouped according to the World Health Organization (WHO) classification [27] as follows: underweight $\left(<18.5 \mathrm{~kg} / \mathrm{m}^{2}\right)$; normo-overweight $\left(18.5-29.9 \mathrm{~kg} / \mathrm{m}^{2}\right)$; or obese $\left(>30 \mathrm{~kg} / \mathrm{m}^{2}\right)$. Also evaluated were the following variables: tumour extension and location; previous radiotherapy or chemo-radiotherapy; surgery type; automatic suture use; neck dissection; voice prosthesis placement; preoperative and postoperative haemoglobin levels (according to WHO [28] anaemia criteria); and preoperative albumin and protein levels. Table 1 summarizes the patient characteristics.

\section{CSMA measurements}

All images, in Digital Imaging and Communications in Medicine (DICOM) format, were anonymized by a person not involved in the study, for analysis by a single researcher (MC), who had previously received training guided by the Radiodiagnosis Department.

The CSMA was measured from CT or positron emission tomography (PET-CT) images obtained in the 3 months prior to surgery. Images were analysed using Image $\mathbf{J}$ (software v1.44p) [29] and Fiji accessories [30]. The axial slice corresponding to C3 was selected following Swartz et al.'s [16] guidelines, i.e., axial C3 slices were scrolled through in the caudo-cranial direction and selected was the first slice that fully showed the vertebral arch, the transverse processes, and the spinous process. The CSMA was evaluated for the prevertebral and nuchal musculature and sternocleidomastoid muscles. In patients with pathological lymph nodes infiltrating part of the musculature to be evaluated, a theoretical line was drawn to delimit the lymph node, and possible infiltrated muscle tissue was excluded as nonviable. The CSMA was defined as the sum of the areas of each muscle bundle (right and left sternocleidomastoid and perivertebral musculature) at the $\mathrm{C} 3$ level.
Table 1 Patient descriptive characteristics

\begin{tabular}{|c|c|c|}
\hline \multicolumn{2}{|l|}{ Characteristic } & \multirow{2}{*}{$\frac{n(\%) / \text { mean }(\mathrm{SD})}{65.7(10.3)}$} \\
\hline Age (years) & & \\
\hline \multirow[t]{3}{*}{ Tobacco/alcohol use } & None & $1(1.2 \%)$ \\
\hline & Moderate & $14(16.3 \%)$ \\
\hline & Heavy & $71(82.6 \%)$ \\
\hline \multirow[t]{2}{*}{ ASA physical status } & I-II & $41(47.7 \%)$ \\
\hline & III-IV & $45(52.3 \%)$ \\
\hline \multirow[t]{2}{*}{ Diabetes mellitus } & No & $62(72.1 \%)$ \\
\hline & Yes & $24(27.9 \%)$ \\
\hline Body mass index $\left(\mathrm{kg} / \mathrm{m}^{2}\right)$ & & $25.4(4.7)$ \\
\hline \multirow[t]{3}{*}{ Subsite location } & Supraglottis & $24(27.9 \%)$ \\
\hline & Glottis & $51(59.3 \%)$ \\
\hline & Hypopharynx & $11(12.8 \%)$ \\
\hline \multirow[t]{3}{*}{ Tumour stage (pT) } & pT2 & $12(14.0 \%)$ \\
\hline & pT3 & $19(22.1 \%)$ \\
\hline & pT4 & $55(64.0 \%)$ \\
\hline \multirow[t]{2}{*}{ Previous radiotherapy } & No & $43(50.0 \%)$ \\
\hline & Yes & $43(50.0 \%)$ \\
\hline \multirow[t]{2}{*}{ Surgery type } & Simple TL & $67(77.9 \%)$ \\
\hline & $\begin{array}{l}\text { Extended } \\
\text { TL } \pm \text { recon- } \\
\text { struction }\end{array}$ & $19(22.1 \%)$ \\
\hline \multirow[t]{3}{*}{ Neck dissection } & No & $12(14.0 \%)$ \\
\hline & Unilateral & $12(14.0 \%)$ \\
\hline & Bilateral & $62(72.1 \%)$ \\
\hline \multirow[t]{2}{*}{ Voice prosthesis } & No & $76(88.4 \%)$ \\
\hline & Yes & $10(11.6 \%)$ \\
\hline \multirow[t]{2}{*}{ Automatic suture } & No & $56(65.1 \%)$ \\
\hline & Yes & $30(34.9 \%)$ \\
\hline Preoperative haemoglobin (g/L) & & $140.2(19.4)$ \\
\hline Postoperative haemoglobin (g/L) & & $109.4(15.4)$ \\
\hline Preoperative protein $(\mathrm{g} / \mathrm{L})^{\dagger}$ & & $64.9(9.4)$ \\
\hline Preoperative albumin $(\mathrm{g} / \mathrm{L})^{\ddagger}$ & & $38.6(5.3)$ \\
\hline
\end{tabular}

ASA American Society of Anesthesiologists, $T L$ total laryngectomy

†Data available from 44 patients

\$Data available from 46 patients

Intraobserver and interobserver validation studies of 10 CT images were based on a repeat analysis and an analysis by a different investigator (CR), respectively. Correlation coefficients were 0.95 or greater for measurements at the $\mathrm{C} 3$ level. Figure S1 (supplementary material) shows the correlations obtained in the validation studies.

\section{Statistical analysis}

SPSS version 17.0 was used for data analysis. Results were considered to be statistically significant at $p<0.05$.

A recursive partitioning analysis (RPA) using the classification and regression tree (CRT) method was used to 
obtain a cut-off point to categorize the continuous CSMA variable (independent variable) according to PCF formation (dependent variable). Patients with CSMA values below the cut-off obtained with the RPA were considered sarcopenic.

A univariate analysis of PCF formation was performed for each evaluated variable, including the CSMA categories obtained in the RPA, using either the Chi-square test or Fisher's exact test depending on the application conditions. A multivariate analysis was performed with a logistic regression model, considering PCF as the dependent variable, and the remaining variables as independent variables. We excluded of the multivariate analysis the preoperative albumin and protein levels due to a lack of data for 40 and 42 patients, respectively. The patient who made no use of alcohol or tobacco $(n=1)$ was included in the moderate alcohol/tobacco use group.

To validate our results, the study was repeated, this time measuring the CSMA at L3 using the Swartz et al. [16] formula and calculating the SMMI.

CSMA values were analysed according to the different clinical variables using the Student's $t$ test or the analysis of variance (ANOVA) test. Correlation between continuous variables was evaluated using Pearson's correlation coefficient.

\section{Results}

\section{PCF and sarcopenia}

A total of 21 patients (24.4\%) developed PCFs after TL. Considering PCF formation as the dependent variable, the RPA cut-off point for the CSMA at C3 was $35.5 \mathrm{~cm}^{2}$. According to this threshold value, 18 patients (20.9\%) presented low SMM, and of these, 9 patients (50.0\%) developed PCFs; of the 68 patients with a normal SMM (79.1\%), 12 (17.6\%) developed PCFs. The risk of PCF formation was thus 4.67 times greater in low SMM patients than in patients with normal SMM (95\% CI 1.53-14.23; $p=0.007)$.

Table 2 shows the percentage of patients with PCF formation according to the different analysed variables. Apart from the CSMA at $\mathrm{C} 3$, tumour location, surgery type, and suture type proved to be significantly related to PCF formation. Thus, PCF frequency was greater for hypopharyngeal tumours $(63.6 \%)$ than for supraglottic tumours $(20.8 \%)$ or glottic tumours $(17.6 \%)(p=0.008)$; for extended TL with pharyngectomy $(52.6 \%)$ than for simple TL (16.4\%) $(p=0.002)$; and for manual suture $(32.1 \%)$ than for automatic suture $(10.0 \%)(p=0.023)$.

Table 3 shows the results of the multivariate study, considering PCF formation as the dependent variable and the remaining variables as independent variables. The results show that the CSMA at C3 was the only variable that was significantly associated with PCF risk: the hazard ratio (HR) for PCF formation in patients with a CSMA at C3 of $\leq 35.5 \mathrm{~cm} 2$ was 9.88 times greater than for patients with a CSMA at C3 of $>35.5 \mathrm{~cm}^{2}$ (95\% CI: $1.40-69.73$; $p=0.022$ ).

The study was repeated using the standard Swartz et al. [16] approach to measuring sarcopenia, based on C3-toL3 conversion of the CSMA and calculating the SMMI by dividing the obtained value by the squared patient height. The RPA cut-off point based on the SMMI value and PCF formation was $47.7 \mathrm{~cm}^{2} / \mathrm{m}^{2}$; accordingly, $46.5 \%(\mathrm{n}=40)$ of patients had decreased SMM, and of these, 37.5\% $(n=15)$ developed PCFs, compared to $13.0 \%$ of 46 patients with normal SMM. PCF risk was 4.00 times greater in patients with low SMM than in patients with normal SMM (95\% CI $1.37-11.67 ; p=0.011$ ). Table $\mathrm{S} 1$ (supplementary material) shows the multivariate analysis results, with the evaluation of SMM according to the SMMI included as an independent variable; as was the case for the CSMA at C3, the only variable that was significantly associated with PCF risk was low SMM. This risk was 8.5 times greater for patients with an SMMI of $\leq 47.7 \mathrm{~cm}^{2} / \mathrm{m}^{2}$ than for patients with an SMMI of $>47.7 \mathrm{~cm}^{2} / \mathrm{m}^{2}(95 \%$ CI $1.22-59.36 ; p=0.031)$.

\section{Patients with low SMM}

Table 4 shows the proportion of patients with low SMM measured according to the CSMA at $\mathrm{C} 3$ for each studied variable. Table $\mathrm{S} 2$ (supplementary material) shows values for the CSMA at $\mathrm{C} 3$ expressed as the mean (SD) for each variable.

Differences were observed according to BMI, surgery extension, the use of automatic suture, and preoperative anaemia and hypoalbuminemia. As for BMI, the higher the value, the greater the observed CSMA at C3 $(p=0.0001)$; based on the WHO BMI classification, $87.5 \%$ of underweight, $17.5 \%$ of normo-overweight, and $0.0 \%$ of obese patients were observed to have low SMM $(p=0.0001)$. Patients with extended surgeries suffered more SMM depletion than patients with simple TL (47.4\% versus $13.4 \%$, $p=0.003)$. In the group of patients in which an automatic suture was used, the prevalence of SMM depletion was lower than in patients sutured manually (3.3\% versus $30.4 \%$ ).

Also, patients with preoperative anaemia presented more risk of low SMM, observed in $38.5 \%$ of those patients compared to $13.3 \%$ for patients without anaemia $(p=0.009)$. Even though the available data regarding preoperative albumin levels were limited, $50.0 \%$ of patients with values below $35 \mathrm{~g} / \mathrm{L}$ presented low SMM, while for patients with normal values, it was of $15.6 \%(p=0.027)$. No differences were observed regarding patients with low SMM as a function of previous radiotherapy treatment $(p=0.112)$. 
Table 2 Univariate analysis of patients with pharyngocutaneous fistula

\begin{tabular}{|c|c|c|c|}
\hline \multicolumn{2}{|l|}{ Characteristic } & \multirow{2}{*}{$\frac{\% \mathrm{PCF}}{23.8}$} & \multirow{2}{*}{$\frac{p \text { value }}{0.898}$} \\
\hline Age & $\leq 65$ years & & \\
\hline & $>65$ years & 25.0 & \\
\hline \multirow[t]{2}{*}{ Tobacco/alcohol use } & Moderate & 33.3 & 0.508 \\
\hline & Heavy & 22.5 & \\
\hline \multirow[t]{2}{*}{ ASA physical status } & I-II & 24.4 & 0.995 \\
\hline & III-IV & 24.4 & \\
\hline \multirow[t]{2}{*}{ Diabetes mellitus } & No & 24.2 & 0.938 \\
\hline & Yes & 25.0 & \\
\hline \multirow{2}{*}{$\begin{array}{l}\text { CSMA at C3 (low } \\
\left.\qquad \mathrm{SMM}=\leq 35.5 \mathrm{~cm}^{2}\right)\end{array}$} & $\leq 35.5 \mathrm{~cm}^{2}$ & 50.0 & $0.011 *$ \\
\hline & $>35.5 \mathrm{~cm}^{2}$ & 17.6 & \\
\hline \multirow[t]{3}{*}{ Body mass index } & Underweight $\left(<18.5 \mathrm{~kg} / \mathrm{m}^{2}\right)$ & 37.5 & 0.649 \\
\hline & Normo-overweight $\left(18.5-29.9 \mathrm{~kg} / \mathrm{m}^{2}\right)$ & 23.8 & \\
\hline & Obese $\left(>30 \mathrm{~kg} / \mathrm{m}^{2}\right)$ & 20.0 & \\
\hline \multirow[t]{3}{*}{ Subsite location } & Supraglottis & 20.8 & $0.008^{*}$ \\
\hline & Glottis & 17.6 & \\
\hline & Hypopharynx & 63.6 & \\
\hline \multirow[t]{3}{*}{ Tumour stage (pT) } & pT2 & 25.0 & 0.621 \\
\hline & pT3 & 15.8 & \\
\hline & pT4 & 27.3 & \\
\hline \multirow[t]{2}{*}{ Previous radiotherapy } & No & 25.6 & 0.802 \\
\hline & Yes & 23.3 & \\
\hline \multirow[t]{2}{*}{ Surgery type } & Simple TL & 16.4 & $0.002 *$ \\
\hline & Extended $\mathrm{TL} \pm$ reconstruction & 52.6 & \\
\hline \multirow[t]{2}{*}{ Automatic suture } & No & 32.1 & $0.023^{*}$ \\
\hline & Yes & 10.0 & \\
\hline \multirow[t]{3}{*}{ Neck dissection } & No & 25.0 & 1.000 \\
\hline & Unilateral & 25.0 & \\
\hline & Bilateral & 24.2 & \\
\hline \multirow[t]{2}{*}{ Voice prosthesis } & No & 26.3 & 0.439 \\
\hline & Yes & 10.0 & \\
\hline \multirow[t]{2}{*}{ Preoperative protein ${ }^{\dagger}$} & $\leq 60 \mathrm{~g} / \mathrm{L}$ & 23.1 & 1.000 \\
\hline & $>60 \mathrm{~g} / \mathrm{L}$ & 19.4 & \\
\hline \multirow[t]{2}{*}{ Preoperative albumin ${ }^{*}$} & $\leq 35 \mathrm{~g} / \mathrm{L}$ & 21.4 & 1.000 \\
\hline & $>35 \mathrm{~g} / \mathrm{L}$ & 18.8 & \\
\hline \multirow[t]{2}{*}{ Preoperative anaemia } & No & 23.3 & 0.722 \\
\hline & Yes & 26.9 & \\
\hline \multirow[t]{2}{*}{ Postoperative anaemia } & No & 14.3 & 1.000 \\
\hline & Yes & 25.3 & \\
\hline
\end{tabular}

ASA American Society of Anesthesiologists, C3 3rd cervical vertebra, CSMA cross-sectional muscle area, $P C F$ pharyngocutaneous fistula, $S M M$ skeletal muscle mass, $T L$ total laryngectomy

* Statistical significance $p<0.05$

${ }^{\dagger}$ Data available from 44 patients

*Data available from 46 patients

\section{Discussion}

\section{Low SMM prevalence}

In our study of the relationship between low SMM and PCF formation after treatment with TL in male patients, SMM was evaluated considering the CSMA calculated from CT slices obtained at the $\mathrm{C} 3$ level. We found, on the basis of direct measurement of the CSMA at C3 and a cut-off point of $35.5 \mathrm{~cm}^{2}$, that $20.9 \%$ of our patients presented low SMM.

In preliminary phases of this study, we observed that the 13 women in our cohort had lower mean CSMA at C3 values 
Table 3 Pharyngocutaneous fistula risk: multivariate analysis including cross-sectional muscle area at the 3 rd cervical vertebra

\begin{tabular}{|c|c|c|c|}
\hline \multicolumn{2}{|l|}{ Characteristic } & \multirow{2}{*}{$\frac{\text { PCF HR (CI 95\%) }}{0.97(0.90-1.05)}$} & \multirow{2}{*}{$\frac{p \text { value }}{0.488}$} \\
\hline Age & (Continuous variable) & & \\
\hline \multirow[t]{2}{*}{ Tobacco/alcohol use } & Moderate & 1 & \multirow[t]{2}{*}{0.051} \\
\hline & Heavy & $0.13(0.02-1.01)$ & \\
\hline \multirow[t]{2}{*}{ ASA physical status } & I-II & 1 & \multirow[t]{2}{*}{0.633} \\
\hline & III-IV & $0.69(0.15-3.14)$ & \\
\hline \multirow[t]{2}{*}{ Diabetes mellitus } & No & 1 & \multirow[t]{2}{*}{0.144} \\
\hline & Yes & $3.27(0.67-15.96)$ & \\
\hline Body mass index $\left(\mathrm{kg} / \mathrm{m}^{2}\right)$ & (Continuous variable) & $1.12(0.94-1.33)$ & 0.202 \\
\hline \multirow{2}{*}{$\begin{array}{l}\text { CSMA at C3 (low } \\
\left.\qquad \mathrm{SMM}=\leq 35.5 \mathrm{~cm}^{2}\right)\end{array}$} & $>35.5 \mathrm{~cm}^{2}$ & 1 & \multirow[t]{2}{*}{$0.022 *$} \\
\hline & $\leq 35.5 \mathrm{~cm}^{2}$ & $9.88(1.40-69.73)$ & \\
\hline \multirow[t]{3}{*}{ Subsite location } & Supraglottis & 1 & \\
\hline & Glottis & $2.62(0.38-17.90)$ & 0.326 \\
\hline & Hypopharynx & $6.41(0.49-83.85)$ & 0.156 \\
\hline \multirow[t]{3}{*}{ Tumour stage (pT) } & pT2 & 1 & \\
\hline & pT3 & $1.24(0.12-13.08)$ & 0.857 \\
\hline & pT4 & $1.13(0.14-8.88)$ & 0.911 \\
\hline \multirow[t]{2}{*}{ Previous radiotherapy } & No & 1 & \multirow[t]{2}{*}{0.823} \\
\hline & Yes & $0.84(0.17-4.04)$ & \\
\hline \multirow[t]{2}{*}{ Surgery type } & Simple TL & 1 & \multirow[t]{2}{*}{0.171} \\
\hline & Extended $\mathrm{TL} \pm$ reconstruction & $5.75(0.47-70.22)$ & \\
\hline \multirow[t]{2}{*}{ Automatic suture } & No & 1 & \multirow[t]{2}{*}{0.354} \\
\hline & Yes & $0.42(0.06-2.64)$ & \\
\hline \multirow[t]{3}{*}{ Neck dissection } & No & 1 & \\
\hline & Unilateral & $0.30(0.02-4.34)$ & 0.375 \\
\hline & Bilateral & $0.70(0.08-5.78)$ & 0.739 \\
\hline \multirow[t]{2}{*}{ Voice prosthesis } & No & 1 & \multirow[t]{2}{*}{0.415} \\
\hline & Yes & $0.33(0.02-4.77)$ & \\
\hline \multirow[t]{2}{*}{ Preoperative anaemia } & No & 1 & \multirow[t]{2}{*}{0.523} \\
\hline & Yes & $0.58(0.11-3.08)$ & \\
\hline \multirow[t]{2}{*}{ Postoperative anaemia } & No & 1 & \multirow[t]{2}{*}{0.510} \\
\hline & Yes & $2.29(0.19-27.02)$ & \\
\hline
\end{tabular}

ASA American Society of Anesthesiologists, C3 3rd cervical vertebra, CSMA cross-sectional muscle area, $H R$ hazard ratio, $P C F$ pharyngocutaneous fistula, $S M M$ skeletal muscle mass, $T L$ total laryngectomy

*Statistical significance $p<0.05$ than men (30.22 $\mathrm{cm}^{2}$ vs $\left.41.02 \mathrm{~cm}^{2} ; p=0.0001\right)$ (Figure $\mathrm{S} 2$ supplementary material). Given the small number of female patients, it was not possible for us to establish a specific cutoff for women, so we excluded those patients from the study.

Calculating a sex-specific cut-off for men allowed a more restrictive cut-off point to be obtained, which probably is more appropriate for the identification of patients at a higher PCF risk, as, from the perspective of - possibly costly and individualized - prevention, it would seem to be more effective to select a small number of patients at clearly higher risk.

There is little literature on the incidence of SMM depletion determined directly at the $\mathrm{C} 3$ level, as the standard procedure is to calculate the SMMI at L3 from measurements made at C3 (the formula proposed by Swartz et al. [16]).
However, because C3-to-L3 conversion formulas are complicated to use in routine practice, we evaluated the relationship with sarcopenia of the CSMA measured directly at C3. Jung et al. [21] have demonstrated, for patients with HNSCC, that direct CSMA measurement at C3 is a good predictor of overall survival; however, to our knowledge, no other studies evaluate PCF risk according to this determination of sarcopenia.

Our cut-off point was based on PCF formation. Considering the cut-off points most commonly used in the literature [7, 22], the proportion of our cohort presenting low SMM would be $80.2 \%$ according to Prado [22] (cut-offs of $52.4 \mathrm{~cm}^{2} / \mathrm{m}^{2}$ for men and $38.5 \mathrm{~cm}^{2} / \mathrm{m}^{2}$ for women), but only $22.1 \%$ according to Wendrich [7] (a cut-off of $43.2 \mathrm{~cm}^{2}$ / $\mathrm{m}^{2}$ ). Those cut-off values vary greatly, because they were 
Table 4 Percentage of patients with low skeletal muscle mass measured directly at the $3 \mathrm{rd}$ cervical vertebra according to different variables

\begin{tabular}{|c|c|c|c|c|}
\hline \multicolumn{2}{|l|}{ Characteristic } & \multirow{2}{*}{$\frac{n}{42}$} & \multirow{2}{*}{$\frac{\text { Low SMM }(\%)}{19.0}$} & \multirow{2}{*}{$\frac{p \text { value }}{0.675}$} \\
\hline Age (years) & $\leq 65$ & & & \\
\hline & $>65$ & 44 & 22.7 & \\
\hline \multirow[t]{2}{*}{ Tobacco/alcohol use } & Moderate & 15 & 6.7 & 0.177 \\
\hline & Heavy & 71 & 23.9 & \\
\hline \multirow[t]{2}{*}{ ASA physical status } & I-II & 41 & 12.2 & 0.057 \\
\hline & III-IV & 45 & 28.9 & \\
\hline \multirow[t]{2}{*}{ Diabetes mellitus } & No & 62 & 24.2 & 0.232 \\
\hline & Yes & 24 & 12.5 & \\
\hline \multirow[t]{3}{*}{ Body mass index $\left(\mathrm{kg} / \mathrm{m}^{2}\right)$} & Underweight $\left(<18.5 \mathrm{~kg} / \mathrm{m}^{2}\right)$ & 8 & 87.5 & $0.0001^{*}$ \\
\hline & Normo-overweight $\left(18.5-29.9 \mathrm{~kg} / \mathrm{m}^{2}\right)$ & 63 & 17.5 & \\
\hline & Obesity $\left(>30 \mathrm{~kg} / \mathrm{m}^{2}\right)$ & 15 & 0.0 & \\
\hline \multirow[t]{3}{*}{ Subsite location } & Supraglottis & 24 & 25.0 & 0.052 \\
\hline & Glottis & 51 & 13.7 & \\
\hline & Hypopharynx & 11 & 45.5 & \\
\hline \multirow[t]{3}{*}{ Tumour stage (pT) } & pT2 & 12 & 8.3 & 0.399 \\
\hline & pT3 & 19 & 15.8 & \\
\hline & pT4 & 55 & 25.5 & \\
\hline \multirow[t]{2}{*}{ Previous radiotherapy } & No & 43 & 27.9 & 0.112 \\
\hline & Yes & 43 & 14.0 & \\
\hline \multirow[t]{2}{*}{ Surgery type } & Simple TL & 67 & 13.4 & $0.003^{*}$ \\
\hline & Extended $\mathrm{TL} \pm$ reconstruction & 19 & 47.4 & \\
\hline \multirow[t]{2}{*}{ Automatic suture } & No & 56 & 30.4 & $0.003^{*}$ \\
\hline & Yes & 30 & 3.3 & \\
\hline \multirow[t]{3}{*}{ Neck dissection } & No & 12 & 16.7 & 0.917 \\
\hline & Unilateral & 12 & 25.0 & \\
\hline & Bilateral & 62 & 21.0 & \\
\hline \multirow[t]{2}{*}{ Voice prosthesis } & No & 76 & 22.4 & 0.681 \\
\hline & Yes & 10 & 10.0 & \\
\hline \multirow[t]{2}{*}{ Preoperative protein ${ }^{\dagger}$} & $\leq 60 \mathrm{~g} / \mathrm{L}$ & 13 & 15.4 & 0.697 \\
\hline & $>60 \mathrm{~g} / \mathrm{L}$ & 31 & 25.8 & \\
\hline \multirow[t]{2}{*}{ Preoperative albumin } & $\leq 35 \mathrm{~g} / \mathrm{L}$ & 14 & 50.0 & $0.027^{*}$ \\
\hline & $>35 \mathrm{~g} / \mathrm{L}$ & 32 & 15.6 & \\
\hline \multirow[t]{2}{*}{ Preoperative anaemia } & No & 60 & 13.3 & $0.009 *$ \\
\hline & Yes & 26 & 38.5 & \\
\hline \multirow[t]{2}{*}{ Postoperative anaemia } & No & 7 & 14.3 & 1.000 \\
\hline & Yes & 79 & 21.5 & \\
\hline
\end{tabular}

ASA American Society of Anesthesiologists, SMM skeletal muscle mass, $T L$ total laryngectomy

* Statistical significance $p<0.05$

† Data available from 44 patients

\$Data available from 46 patients obtained on the basis of different dependent variables. The study by Prado et al. [22], carried out with a cohort of obese patients who had lung or gastrointestinal tract tumours, focused on determining a threshold that would define a significant association between decreased muscle mass and mortality in such patients, while the study by Wendrich et al. [7], performed in patients with HNSCC, aimed at obtaining a cut-off point related to the dose-limiting toxicity of chemotherapy.

\section{Low SMM as a PCF risk factor}

Of the 86 patients evaluated in our study, 21 (24.4\%) developed PCFs. The univariate analysis showed that low SMM was significantly associated with PCF formation $(p=0.011)$. Corroborating our results for a previous study [6], the other variables associated with PCF formation were tumour location and surgery type, specifically, hypopharyngeal tumours $(p=0.008)$ and extended TL with pharyngectomy 
$(p=0.002)$, respectively. Suture type was another variable associated with PCF formation in the univariate analysis, as manual suture implied a significant PCF risk. Note, however, that we consider this finding to be a consequence of selection bias, as only patients with endolaryngeal tumours treated with simple TL—with a lower a priori PCF risk [31]—were considered candidates for automatic suture closure.

In line with the findings of other authors [9, 32-36], we found no significant relationship between BMI and PCF risk. However, for their multicentre study, Lansaat et al. [3] reported that the PCF rate was 2.7 times higher in underweight patients $\left(\mathrm{BMI}<18 \mathrm{~kg} / \mathrm{m}^{2}\right.$ ) compared to normal weight patients, and Lebo et al. [1] similarly reported a higher PCF rate for underweight patients. Nonetheless, we agree with Prado et al. [22] argument that, since the BMI does not indicate the composition of each weight unit, the information it provides is incomplete. Exemplifying this argument are the $\mathrm{C} 3$ images for two patients in our study shown in Fig. 1: while both patients had the same BMI of $23 \mathrm{~kg} / \mathrm{m}^{2}$, on the basis of their CSMA values of $29.4 \mathrm{~cm}^{2}$ (image A) and $43.9 \mathrm{~cm} 2$ (image B), they are classifiable as low SMM and normal SMM patients, respectively.

The multivariate analysis indicated that low SMM was the only variable that was significantly related to PCF risk, 9.88 times greater for patients with a CSMA of $\leq 35.5 \mathrm{~cm}^{2}$ than for patients with a CSMA of $>35.5 \mathrm{~cm}^{2}(p=0.022)$. When CSMA was included in the multivariate analysis as an independent variable, the relationship that we identified in a previous study [6], namely, between the extent of surgery and PCF risk, no longer held; this finding would indicate that sarcopenia measured directly at $\mathrm{C} 3$ is, of the analysed variables, the most important predictor of PCF risk. It should be noted that the cut-off point used in the RPA was obtained specifically considering PCF formation as the dependent variable. The use of the same variable as a determinant cut-off to segregate the sample and as the dependent variable in the multivariate model is subject to bias. Therefore, studies need to be carried out to validate the paper of low SMM in patients treated with a laryngectomy.

Other authors have found SMM depletion to be associated with PCF formation in patients treated with TL $[9,10]$. Achim et al. [9] analysed the CSMA at L3 for 70 patients treated with TL, finding that patients with sarcopenia developed 7.5 times more complications than patients without sarcopenia (95\% CI 1.56-36.4), and also that PCF incidence was $32 \%$ greater in patients with low SMM (95\% CI 1.13-1.53). For 235 patients treated with TL, Bril et al. [10] used the cut-off point proposed by Wendrich et al. [7] (43.2 $\mathrm{cm}^{2} / \mathrm{m}^{2}$ ) for CSMA at C3 converted to SMMI at L3, observing that SMM was reduced in $46.4 \%$ of cases, and also that patients with low SMM compared to patients with normal muscle mass more frequently developed PCFs $(34.9 \%$ vs $20.6 \% ; p=0.02)$ and more frequently required surgical repair $(p=0.05)$.

Low SMM incidence as a risk factor for PCF was determined to be equivalent for our direct measurement of the CSMA at C3 and for the standard method of C3-to-L3 conversion and SMMI calculation. Our results would therefore suggest that measurement of the CSMA at C3 is a valid method for evaluating muscle mass, and therefore low SMM, in patients with HNSCC, while having the advantage of being a direct measurement that avoids the use of conversion formulas.

\section{Patients with low SMM}

A relationship was observed between BMI and the CSMA at $\mathrm{C} 3$. Analysing percentages according to the WHO [27] BMI classification, we observed that low SMM was far more frequent (87.5\%) in underweight patients
Fig. 1 Images at the 3rd cervical vertebra corresponding to 2 patients with the same body mass index of $23 \mathrm{~kg} / \mathrm{m}^{2}$. The red areas included in the manually designed yellow regions of interest corresponding to perivertebral musculature (labelled as 1 for nuchal and 2 for prevertebral muscles) and sternocleidomastoid muscles (labelled 3 and 4) are added to obtain the cross-sectional muscle area. The cross-sectional muscle areas of $29.4 \mathrm{~cm}^{2}$ in image A and $44 \mathrm{~cm}^{2}$ in image B would classify the patients as having low skeletal muscle mass and normal skeletal muscle mass, respectively
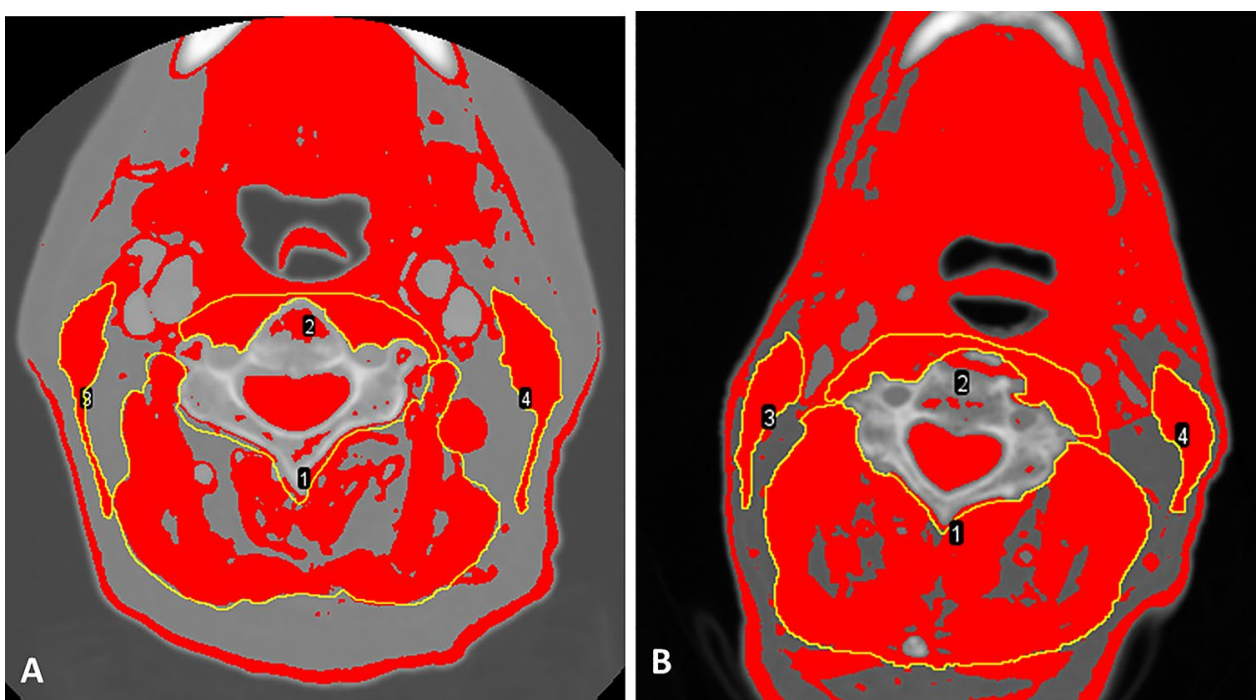
$\left(\mathrm{BMI}<18.5 \mathrm{~kg} / \mathrm{m}^{2}\right)$, and no low SMM cases $(0.0 \%)$ were assessed in obese patients (BMI $>30 \mathrm{~kg} / \mathrm{m}^{2}$ ). Corroborating our results, Cho et al. [37] reported a higher proportion of underweight patients in their depleted SMM group than in their normal SMM group (17\% vs $4 \% ; p<0.001)$.

We found that the depleted SMM rate was higher in patients with extended surgeries. We attribute this finding to a higher tumour stage that requires complex surgeries including pharyngectomies with or without reconstruction. In turn, we believe that patients with advanced tumour stages present sarcopenia as a reflection of suboptimal nutritional status and tumour-related metabolic changes, such as preoperative anaemia or hypoalbuminemia. The increased rate of low SMM in patients sutured manually might be a consequence to the selection bias occurred, because automatic suture is only performed in patients with endolaryngeal tumours.

The main limitation of our study is that, given its retrospective nature, we were unable to evaluate the impact of certain variables that could influence PCF formation, such as weight loss, a history of tracheotomy [32], or perioperative transfusions $[1,4,33,38]$. Another important limitation was the reduced number of patients and its heterogeneity in treatment strategy, which may lead to a selection bias. We were also unable to evaluate our patients' muscle strength, a key aspect of sarcopenia diagnosis according to the EWGSOP [13].

Further studies need to be carried to validate the relationship between the CSMA at C3 and post-TL PCF formation, and to define cut-off points with a greater prognostic capacity.

\section{Conclusions}

On the basis of a definition of low SMM associated with PCF formation, 20.9\% of our cohort had preoperative SMM depletion as determined from the CSMA at C3. Our multivariate study of risk factors for PCF indicated low SMM to be the only independent risk factor: such patients had a near tenfold increased risk of PCF formation. The fact that measuring the CSMA at $\mathrm{C} 3$ obtained results similar to those obtained by calculating the SMMI at L3 would suggest that direct SMM assessment from C3 is a useful approach to evaluating post-TL PCF.

Supplementary Information The online version contains supplementary material available at https://doi.org/10.1007/s00405-021-07127-3.

Author contributions All authors have contributed in the writing or editing of the article.
Funding Open Access Funding provided by Universitat Autonoma de Barcelona. This work was supported by grants from the State $\mathrm{R}+\mathrm{D}+\mathrm{I}$ Plan of the Instituto de Salud Carlos III (FIS PI19/01661) and European Regional Development Fund (A Way to Build Europe).

\section{Declarations}

Conflict of interest The authors declare no conflict of interest to the work submitted for publication.

Availability of data and materials Data are available from the hospital software, SAP.

Code availability Not applicable.

Ethics approval All procedures performed in this study involving human participants were in accordance with the ethical standards of the institutional, regional, and national research committee and with the 1964 Declaration of Helsinki and its later amendments or comparable ethical standards. The study was authorized by our hospital's Clinical Research Ethics Committee [reference 19/126 (OBS)].

Informed consent to participate For this type of study, formal consent was not required.

Consent for publication For this type of study, formal consent was not required.

Open Access This article is licensed under a Creative Commons Attribution 4.0 International License, which permits use, sharing, adaptation, distribution and reproduction in any medium or format, as long as you give appropriate credit to the original author(s) and the source, provide a link to the Creative Commons licence, and indicate if changes were made. The images or other third party material in this article are included in the article's Creative Commons licence, unless indicated otherwise in a credit line to the material. If material is not included in the article's Creative Commons licence and your intended use is not permitted by statutory regulation or exceeds the permitted use, you will need to obtain permission directly from the copyright holder. To view a copy of this licence, visit http://creativecommons.org/licenses/by/4.0/.

\section{References}

1. Lebo NL, Caulley L, Alsaffar H, Corsten MJ, Johnson-Obaseki S (2017) Peri-operative factors predisposing to pharyngocutaneous fistula after total laryngectomy: analysis of a large multi- institutional patient cohort. J Otolaryngol Head Neck Surg 23:46-54. https://doi.org/10.1186/s40463-017-0233-Z

2. Liang JW, Li ZD, Li SC, Fang FQ, Zhao YJ, Li YG (2015) Pharyngocutaneous fistula after total laryngectomy: a systematic review and meta-analysis of risk factors. Auris Nasus Larynx 42(5):353-359. https://doi.org/10.1016/j.anl.2015.04.002

3. Lansaat L, van der Noort V, Bernard SE, Eerenstein SEJ, Plaat BEC, Langeveld TAPM, Lacko M, Hilgers FJM, de Bree R, Takes RP, van den Brekel MWM (2018) Predictive factors for pharyngocutaneous fistulization after total laryngectomy: a Dutch Head and Neck Society audit. Eur Arch Otorhinolaryngol 275(3):783794. https://doi.org/10.1007/s00405-017-4861-8

4. Dedivitis RA, Aires FT, Cernea CR, Brandão LG (2015) Pharyngocutaneous fistula after total laryngectomy: Systematic review 
of risk factors. Head Neck 37(11):1691-1697. https://doi.org/10. 1002/hed.23804

5. Hasan Z, Dwivedi RC, Gunaratne DA, Virk SA, Palme CE, Riffat F (2017) Systematic review and meta-analysis of the complications of salvage total laryngectomy. Eur J Surg Oncol 43(1):4251. https://doi.org/10.1016/j.ejso.2016.05.017

6. Casasayas M, Sansa A, García-Lorenzo J, López M, Orús C, Peláez X, Quer M, León X (2019) Pharyngocutaneous fistula after total laryngectomy: multivariate analysis of risk factors and a severity-based classification proposal. Eur Arch OtoRhino-Laryngol 276(1):143-151. https://doi.org/10.1007/ s00405-018-5200-4

7. Wendrich AW, Swartz JE, Bril SI, Wegner I, De GA, Smid EJ, De BR, Pothen AJ (2017) Low skeletal muscle mass is a predictive factor for chemotherapy dose-limiting toxicity in patients with locally advanced head and neck cancer. Oral Oncol 71:26-33. https://doi.org/10.1016/j.oraloncology.2017.05.012

8. Bozkurt G, Elhassan HA, Mahmutoğlu AS, Çelebi İ, Mcleod RWJ, Soytaş P, Erol ZN, Sözen E (2018) Neck Muscle Mass Index as a predictor of post-laryngectomy wound complications. Ann Otol Rhinol Laryngol 127(11):841-847. https://doi.org/10.1177/ 0003489418798660

9. Achim V, Bash J, Mowery A, Guimaraes AR, Li R, Schindler J, Wax M, Andersen P, Clayburgh D (2017) Prognostic indication of sarcopenia for wound complication. JAMA Otolaryngol Head Neck Surg 143(12):1159-1165. https://doi.org/10.1001/jamaoto. 2017.0547

10. Bril SI, Pezier TF, Tijink BM, Janssen LM, Braunius WW, de Bree R (2019) Preoperative low skeletal muscle mass as a risk factor for pharyngocutaneous fistula and decreased overall survival in patients undergoing total laryngectomy. Head Neck 41(6):17451755. https://doi.org/10.1002/hed.25638

11. Huiskamp LFJ, Chargi N, Devriese LA, de Jong PA, de Bree R (2020) The predictive and prognostic value of low skeletal muscle mass for dose-limiting toxicity and survival in head and neck cancer patients receiving concomitant cetuximab and radiotherapy. Eur Arch Otorhinolaryngol 277(10):2847-2858. https://doi.org/ 10.1007/s00405-020-05972-2

12. Willemsen ACH, Hoeben A, Lalisang RI, Van Helvoort A, Wesseling FWR, Hoebers F, Baijens LWJ, Schols AMWJ (2020) Disease-induced and treatment-induced alterations in body composition in locally advanced head and neck squamous cell carcinoma. J Cachexia Sarcopenia Muscle 11(1):145-159. https://doi.org/10. 1002/jcsm. 12487

13. Cruz-Jentoft AJ, Bahat G, Bauer J, Boirie $Y$, Bruyère $O$, Cederholm T, Cooper C, Landi F, Rolland Y, Sayer AA, Schneider SM, Sieber CC, Topinkova E, Vandewoude M, Visser M, Zamboni M, Bautmans I, Baeyens JP, Cesari M, Cherubini A, Kanis J, Maggio M, Martin F, Michel JP, Pitkala K, Reginster JY, Rizzoli R, Sánchez-Rodríguez D, Schols J (2019) Sarcopenia: revised European consensus on definition and diagnosis. Age Ageing 48(1):16-31. https://doi.org/10.1093/ageing/afy169

14. Chamchod S, Fuller CD, Mohamed ASR, Sc M, Grossberg A, Messer JA, Heukelom J, Gunn GB, Kantor ME, Ba HE, Garden AS, Rosenthal DI (2016) Quantitative body mass characterization before and after head and neck cancer radiotherapy : a challenge of height-weight formulae using computed tomography measurement. Oral Oncol 61:62-69. https://doi.org/10.1016/j.oraloncolo gy.2016.08.012

15. Jung AR, Roh JL, Kim JS, Kim SB, Choi SH, Nam SY, Kim SY (2019) Prognostic value of body composition on recurrence and survival of advanced-stage head and neck cancer. Eur J Cancer 116:98-106. https://doi.org/10.1016/j.ejca.2019.05.006

16. Swartz JE, Pothen AJ, Wegner I, Smid EJ, Swart KMA, De BR, Leenen LPH, Grolman W (2016) Feasibility of using head and neck CT imaging to assess skeletal muscle mass in head and neck cancer patients. Oral Oncol 62:28-33. https://doi.org/10.1016/j. oraloncology.2016.09.006

17. Zwart AT, van der Hoorn A, van Ooijen PMA, Steenbakkers RJHM, de Bock GH, Halmos GB (2019) CT-measured skeletal muscle mass used to assess frailty in patients with head and neck cancer. J Cachexia Sarcopenia Muscle 10(5):1060-1069. https:// doi.org/10.1002/jcsm.12443

18. Chargi N, Bril SI, Emmelot-Vonk MH, de Bree R (2019) Sarcopenia is a prognostic factor for overall survival in elderly patients with head-and-neck cancer. Eur Arch Otorhinolaryngol 276(5):1475-1486. https://doi.org/10.1007/s00405-019-05361-4

19. Ganju RG, Morse R, Hoover A, Tennapel M, Lominska CE (2019) The impact of sarcopenia on tolerance of radiation and outcome in patients with head and neck cancer receiving chemoradiation. Radiother Oncol 137:117-124. https://doi.org/10.1016/j.radonc. 2019.04.023

20. van Rijn-Dekker MI, van den Bosch L, van den Hoek JGM, Bijl HP, van Aken ESM, van der Hoorn A, Oosting SF, Halmos GB, Witjes MJH, van der Laan HP, Langendijk JA, Steenbakkers RJHM (2020) Impact of sarcopenia on survival and late toxicity in head and neck cancer patients treated with radiotherapy. Radiother Oncol 147:103-110. https://doi.org/10.1016/j.radonc. 2020.03.014

21. Jung AR, Roh JL, Kim JS, Choi SH, Nam SY, Kim SY (2019) Efficacy of head and neck computed tomography for skeletal muscle mass estimation in patients with head and neck cancer. Oral Oncol 95:95-99. https://doi.org/10.1016/j.oraloncology.2019.06.009

22. Prado CM, Lieffers JR, McCargar LJ, Reiman T, Sawyer MB, Martin L, Baracos VE (2008) Prevalence and clinical implications of sarcopenic obesity in patients with solid tumours of the respiratory and gastrointestinal tracts: a population-based study. Lancet Oncol 9(7):629-635. https://doi.org/10.1016/S1470-2045(08) 70153-0

23. Grossberg A, Chamchod S, Fuller C, Mohamed A, Heukelom J, Eichelberger H, Kantor M, Hutcheson K, Gunn G, Garden A, Frank S, Phan J, Beadle B, Skinner H, Morrison W, Rosenthal D (2016) Association of body composition with survival and locoregional control of radiotherapy-treated head and neck squamous cell carcinoma. JAMA Oncol 2(6):782-789. https://doi.org/10. 1001/jamaoncol.2015.6339

24. Fattouh M, Chang GY, Ow TJ, Shifteh K, Rosenblatt G, Patel VM, Smith RV, Prystowsky MB, Schlecht NF (2020) Association between pretreatment obesity, sarcopenia, and survival in patients with head and neck cancer. Head Neck 41(3):707-714. https://doi. org/10.1002/hed.25420.ASSOCIATION

25. Stone L, Olson B, Mowery A, Krasnow S, Jiang A, Li R, Schindler J, Wax MK, Andersen P, Marks D, Achim V, Clayburgh D (2019) Association between sarcopenia and mortality in patients undergoing surgical excision of head and neck cancer. JAMA Otolaryngol Head Neck Surg 145(7):647-654. https://doi.org/10.1001/ jamaoto.2019.1185

26. Sumarroca A, Rodríguez-Bauzà E, Lop-Gros J, García J, López M, Quer M, León X (2018) Repair of post-laryngectomy pharyngocutaneous fistulas using a pectoralis major flap. Braz J Otorhinolaryngol 85(3):351-356. https://doi.org/10.1016/j.bjorl.2018. 03.002

27. World Health Organization (2000) Obesity: preventing and managing the global epidemic

28. World Health Organization (2011) Haemoglobin concentrations for the diagnosis of anaemia and assessment of severity. Vitamin and Mineral Nutrition Information System. 2011 (WHO/NMH/ NHD/MNM/11.1). http://www.who.int/vmnis/indicators/haemo globin.pdf (accessed [date]) 
29. Schneider CA, Rasband WS, Eliceiri KW (2012) NIH Image to ImageJ: 25 years of image analysis. Nat Methods 9(7):671-675

30. Schindelin J, Arganda-Carreras I, Frise E, Kaynig V, Longair M, Pietzsch T, Preibisch S, Rueden C, Saalfeld S, Schmid B, Tinevez J-Y, White DJ, Hartenstein V, Eliceiri K, Tomancak P, Cardona A (2012) Fiji: an open-source platform for biological-image analysis. Nat Methods 9:676-682. https://doi.org/10.1038/nmeth.2019

31. Sansa-Perna A, Casasayas-Plass M, Rovira-Martínez C, LópezVilas M, García-Lorenzo J, Quer-Agusti M, León-Vintró X (2020) Pharyngeal closure after a total laryngectomy: mechanical versus manual technique. J Laryngol Otol 134(7):626-631. https://doi. org/10.1017/S0022215120001371

32. Benson EM, Hirata RM, Thompson CB, Ha PK, Fakhry C, Saunders JR, Califano JA, Arnaoutakis D, Levine M, Tang M, Neuner G, Messing BP, Blanco RGF (2015) Pharyngocutaneous fistula after total laryngectomy: a single-institution experience, 2001-2012. Am J Otolaryngol Head Neck Med Surg 36(1):24-31. https://doi.org/10.1016/j.amjoto.2014.08.017

33. Kim DY, Roh JL, Choi JW, Choi SH, Nam SY, Kim SY (2014) Risk factors and survival outcomes for patients with anastomotic leakage after surgery for head and neck squamous cell carcinoma. Clin Exp Otorhinolaryngol 7(1):36-41. https://doi.org/10.3342/ ceo.2014.7.1.36

34. Virtaniemi JA, Kumpulainen EJ, Hirvikoski PP, Johansson RT, Kosma V-M (2001) The incidence and etiology of postlaryngectomy pharyngocutaneous fistulae. Head Neck 23(1):29-33. https://
doi.org/10.1002/1097-0347(200101)23:1\%3c29::AID-HED5\% 3e3.0.CO;2-P

35. Palomar-Asenjo V, Sarroca Capell E, Tobías Gómez S, Pérez Hernández I, Palomar-García V (2008) Pharyngocutaneous fistula following total laryngectomy. A case-control study of risk factors implicated in its onset. Acta Otorrinolaringol Espanola 59(10):480-484

36. Cavalot AL, Gervasio CF, Nazionale G, Albera R, Bussi M, Staffieri A, Ferrero V, Cortesina G (2000) Pharyngocutaneous fistula as a complication of total laryngectomy: review of the literature and analysis of case records. Otolaryngol Head Neck Surg 123(5):587-592. https://doi.org/10.1067/mhn.2000.110617

37. Cho Y, Kim JW, Keum KC, Lee CG, Jeung HC (2018) Prognostic significance of sarcopenia with inflammation in patients with head and neck cancer who underwent definitive chemoradiotherapy. Front Oncol 22(8):457. https://doi.org/10.3389/fonc.2018.00457

38. Erdag MA, Arslanoglu S, Onal K, Songu M, Tuylu AO (2013) Pharyngocutaneous fistula following total laryngectomy: multivariate analysis of risk factors. Eur Arch Otorhinolaryngol 270(1):173-179. https://doi.org/10.1007/s00405-012-2111-7

Publisher's Note Springer Nature remains neutral with regard to jurisdictional claims in published maps and institutional affiliations. 